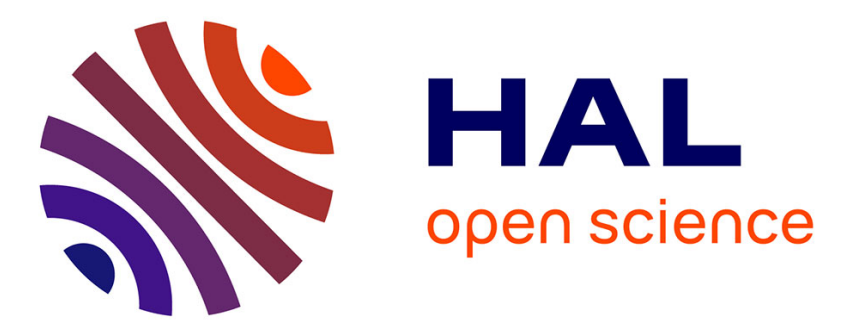

\title{
A 3D electrical resistivity tomography survey to characterise the structure of a albeluvic tonguing horizon composed of distinct elementary pedological volumes \\ Maud Seger, R. Guérin, A. Frison, H. Bourennane, G. Richard, I. Cousin
}

\section{To cite this version:}

Maud Seger, R. Guérin, A. Frison, H. Bourennane, G. Richard, et al.. A 3D electrical resistivity tomography survey to characterise the structure of a albeluvic tonguing horizon composed of distinct elementary pedological volumes. Geoderma, 2014, 219, pp.168-176. 10.1016/j.geoderma.2013.12.018 . hal-01196395

\section{HAL Id: hal-01196395 \\ https://hal.science/hal-01196395}

Submitted on 27 May 2020

HAL is a multi-disciplinary open access archive for the deposit and dissemination of scientific research documents, whether they are published or not. The documents may come from teaching and research institutions in France or abroad, or from public or private research centers.
L'archive ouverte pluridisciplinaire HAL, est destinée au dépôt et à la diffusion de documents scientifiques de niveau recherche, publiés ou non, émanant des établissements d'enseignement et de recherche français ou étrangers, des laboratoires publics ou privés. 
1 A 3D electrical resistivity tomography survey to characterise the structure of a 2 albeluvic tonguing horizon composed of distinct elementary pedological 3 volumes

4

5 M. Séger ${ }^{\mathrm{a},{ }^{\star}}$, R. Guérin ${ }^{\mathrm{b}}$, A. Frison ${ }^{\mathrm{a}}$, H. Bourennane ${ }^{\mathrm{a}}$, G. Richard ${ }^{\mathrm{a}}$, I. Cousin $^{\mathrm{a}}$ 6

7 a INRA, Unité de Science du Sol, 2163 Avenue de la pomme de Pin, CS 40001

8 Ardon, 45075 ORLEANS Cedex 2, France

$9{ }^{b}$ Université Pierre et Marie Curie-Paris 6, UMR 7619 Sisyphe, case 105, 75252 Paris 10 Cedex 05, France

$12{ }^{*}$ Corresponding author:

13 Tel.: + 33238418046

14 Fax: +33238417869

15 E-mail address: maud.seger@orleans.inra.fr (M. Séger)

Financial Support:

19 The authors wish to thank the Region Centre for the funding of the PhD thesis of 20 Anthony Frison and the program SPATIOFLUX. 
Version définitive du manuscrit publié dans / Final version of the manuscript published in :

1 Abstract

2

3 Water and gas transfer in porous media like soils are determined by their porous 4 network, described by their structure. In soil, the horizon is usually considered to be 5 elementary and homogeneous functioning system in the description of gas and water 6 functioning. However, in some cases, a horizon is heterogeneous, and its structure is 7 defined by the 3D arrangement of Elementary Pedological Volumes (EPVs). The 8 horizon needs to be described in three dimensions to improve the characterisation of 9 the structure and, consequently, the prediction of its hydraulic functioning. The aim of 10 this study was to determine the feasibility of describing the 3D structure of a heterogeneous albeluvic tonguing soil horizon composed of a juxtaposition of silty white and clayey ochre EPVs, using 3D electrical resistivity tomography (ERT). Electrical measurements were compared with geostatistical analyses from soil photographs. We demonstrated that the resistivity of the white EPVs was greater 15 than that of the ochre EPVs. In addition, the general soil structure and organisation of 16 the soil horizon could be derived from the electrical resistivity data. We proposed a method to discretise the soil electrical resistivity into a binary system that corresponded to white and ochre volumes. Finally, a 3D representation of the soil structure was created that could be used to improve soil hydraulic models.

21 Keywords: soil electrical resistivity, heterogeneous structure, Elementary Pedological Volumes, electrical resistivity tomography, degraded horizon, hydraulic modelling, geostatistical filtering, kriging component 
Version définitive du manuscrit publié dans / Final version of the manuscript published in :

1 1. Introduction

Soil naturally filters water as it is transported to groundwater reservoirs. Thus, soil structure influences water storage and transfer and gas diffusivity, which have major environmental and agronomic consequences. Therefore, it is important to know the soil structure to predict soil hydraulic functions.

Typically, soil horizons are considered to be elementary and homogeneous systems for the pedological description of soils (Jamagne and King, 2003; Bockheim et al., 2005). Furthermore, soil horizons are used for modelling water transfer properties and consist in the basic information of soil databases, such as the UNSODA $^{1}$ (Nemes et al., 2001) or HYPRES ${ }^{2}$ (Wösten et al., 1999) databases, which are populated with soil data at the horizon scale. Nevertheless, in some cases, the horizon is heterogeneous and its structure, at the so-called $n$ scale, is defined by the arrangement of pedological volumes at the $(n-1)$ scale. Heterogeneous horizons are very common and include ploughed horizons (Richard et al., 2001), stony horizons (Cousin et al., 2003), or horizons with vertical leaching tongues (Diab et al., 1988; Frison et al., 2009).

To improve the characterisation of the soil structure and, consequently, its hydraulic function, the soil horizon needs to be described in three dimensions (3D). Several methods already exist to characterise heterogeneous soil horizons. These methods are based on (i) the visual description of the soil profile in a ploughed horizon (Roger-Estrade et al., 2004), (ii) the characterisation of water infiltration or (iii) soil property measurements, such as bulk density, porosity, and penetrability. However, these methods do not describe the horizon structure in 3D. Serial sections, X-ray tomography (XRT) and electrical resistivity tomography (ERT) are three techniques that can be used to obtain a 3D description of soil structure. The serial sections method is conducted by taking photographs of successive thin twodimensional (2D) slices of an impregnated (e.g., with dye tracer - Trojan and Linden, 1998; Forrer et al., 2000) or non-impregnated (Pereira and FitzPatrick, 1998) volume of soil. These images are superimposed to reproduce the 3D soil volume (e.g. Cousin et al., 1996). This method can be applied to obtain a resolution from a few hundred micrometres (Cousin et al., 1996) to approximately one centimetre in the

\footnotetext{
${ }^{1}$ UNsaturated SOil hydraulic DAtabase

${ }^{2}$ HYdraulic PRoperties of European Soils
} 
Version définitive du manuscrit publié dans / Final version of the manuscript published in :

1 field (Vogel et al., 2002). Since the work reported by Petrovic et al. (1982), XRT had

2 enabled researchers to characterise soil structure on large undisturbed samples of a

3 few cubic decimetres. Similar to the serial sections method, the XRT method is often

4 used to obtain topological information and porous network descriptions of the studied 5 sample. Unfortunately, the serial sections and XRT methods require destructive 6 sampling, which does not allow monitoring of the soil structure evolution with time.

7 Therefore, the use of non-destructive techniques should be encouraged. Among the 8 non-destructive techniques, ERT is of primary interest for obtaining a 3D 9 representation of the subsurface (Dahlin, 2001). ERT has been used to describe 10 changes in bulk density (e.g. Abu-Hassanein et al., 1996; Besson et al., 2004), stony 11 inclusions (e.g. Rey et al., 2006), and soil morphological structures (Séger et al., 12 2009).

13 The aim of this work was to determine the 3D structure of a heterogeneous 14 albeluvic tonguinghorizon for an area of approximately one square metre using 3D 15 ERT. At this site, the heterogeneity is a juxtaposition of ochre clay and white silt 16 pedological volumes of a few cubic centimetres, called 'Elementary Pedological measurements for describing the clay and silt volume arrangements.

\section{Materials and methods} cultivated field. This soil is an Albeluvisol (WRB, 1998) that was developed on aeolian Quaternary loam that was deposited over an Eocene clay layer. This soil is

\subsection{Study site}

\subsubsection{Soil description}

The studied soil is located on the crest of the Yonne plateau, France, in a characterised by the three following horizons (Figure 1). 
Version définitive du manuscrit publié dans / Final version of the manuscript published in :

1 - From 0.00 to $0.35 \mathrm{~m}$, a silty, brown to grey, ploughed A horizon with a granular

2 structure that becomes more massive below a depth of $0.3 \mathrm{~m}$.

3 - From 0.35 to $0.60 \mathrm{~m}$, a transitional albeluvic tonguing E\&Bt horizon with a

4 polyhedral structure that is characterised by the juxtaposition of different sub-units 5 (Frison et al., 2009) from the upper and the lower horizons. These subunits include white-grey (10YR8/2 to 10YR7/1) to pale-brown (10YR7/4) albeluvic tongues that are called "white Elementary Pedological Volumes (EPVs)" and ochre (10YR5/6 with 10YR5/8) volumes that are called "ochre EPVs". Black concretions and inclusions were observed in the ochre EPVs. This E\&Bt horizon, that exhibited the maximum structural heterogeneity (Diab et al., 1988; Montagne et al., 2007, 2008; Frison et al., 2009) was the object of this study.

- From 0.60 to $1.00 \mathrm{~m}$, a Bt horizon that exhibits white albeluvic tongues (equivalent to those of the E\&Bt horizon) in the ochre matrix. The structure of this horizon is more prismatic than that of the E\&Bt horizon.

15

\subsubsection{EPV description}

Several EPVs $\left(15-30 \mathrm{~cm}^{3}\right)$ were collected from the E\&Bt horizon in the field by gently separating this soil by hand according to colour. These samples were collected at two depths, from 0.35 to 0.45 and from 0.45 to $0.55 \mathrm{~m}$. The samples were stored at their field moisture contents at $4^{\circ} \mathrm{C}$ in hermetic boxes prior to conducting any measurements. The water content was measured on a mass basis for each EPV using approximately six replicates. The bulk density was determined using the kerosene method (Blake and Hartge, 1986) on approximately ten replicates. The clay content of each EPV was determined by blending ten EPVs and using Robison's pipette method following ultrasonic dispersion in water and the addition of $\mathrm{NaPO}_{3}$ and $\mathrm{Na}_{2} \mathrm{CO}_{3}$ (according to the French normalised protocol, $\mathrm{X} 31$ 107).

The bulk density of the white EPVs was slightly lower than the bulk density of the ochre EPVs (Table 1). The water content in the white EPVs was slightly higher than that in the ochre EPVs. However, in both cases, the water content did not depend on the position of the EPVs in the profile (Table 1). The clay content was higher in the ochre EPVs and increased with depth (Table 1). 
Version définitive du manuscrit publié dans / Final version of the manuscript published in :

\subsection{Field measurements}

\subsubsection{Protocol experiment and colour photographs}

The measurements were realised at the depth 0.35 to 0.55 in the highly heterogeneous E\&Bt horizon. A trench $0.5 \mathrm{~m} \times 1.0 \mathrm{~m}$, with a depth of $1 \mathrm{~m}$ was dug for the people to stay. Before the electrical measurements, the ploughed horizon was removed from the upper surface of the E\&Bt horizon to obtain a regular and planar $\mathrm{x}$ y surface of approximately one square metre. This $x-y$ plane was called "A level" and was located at a depth of $z=0.35 \mathrm{~m}$ (Figure 1). Colour photographs were taken of the A level before conducting electrical measurements. A $0.06 \mathrm{~m}$ layer of the soil was removed to obtain a second $x-y$ surface. This second $x-y$ surface is referred to as " $B$ level" and was at a depth of $z=0.41 \mathrm{~m}$. A second sequence of electrical measurements and colour photographs was collected from the B level. The same procedure was repeated to obtain a third $x-y$ surface at a depth of $z=0.47 \mathrm{~m}$, which is referred to as the "C level". All colour photographs were taken with a digital camera (Panasonic, DMC-FZ5, focal distance 2.8, speed 1/60 s, ISO-150) and with natural sunlight.

\subsubsection{Electrical measurements}

Electrical resistivity measurements were performed with a programmable multi-electrode system that was connected to a resistivity meter (Syscal R1 Plus, IRIS Instruments). Brass electrodes of $2 \mathrm{~mm}$ diameter were positioned on supports and inserted approximately $2 \mathrm{~mm}$ into the soil. To obtain high-quality electrical resistivity measurements, the resistance between the soil and electrode was measured to check if the contacts were reliable and steady. Indeed, it then ensure that the current intensity and resulting potential are high enough to be measured with a correct significativity. Electrodes were positioned far enough from the excavation $(60 \mathrm{~cm})$ to avoid border effects.

Three types of electrode configurations (Figure 2) were employed for the electrical resistivity measurements, including (i) a line of 32 electrodes spaced at $0.03 \mathrm{~m}$ apart (Wen32), (ii) a line of 16 electrodes spaced at $0.03 \mathrm{~m}$ apart (Wen16) and (iii) a regular square grid of 32 electrodes spaced at $0.09 \mathrm{~m}$ apart (Sqr32). The 
1 Wenner- $\alpha$ array was used for the line configurations (Wen32 and Wen16) because it

2 is known to be relatively sensitive to vertical changes and has the best signal-to-

3 noise ratio. In addition, this array type can be used in areas with high background

4 noise (Loke, 2001; Dahlin and Zhou, 2004; Samouëlian et al., 2005), which occurs in

5 the studied E\&Bt horizon. The square array (Sqr32) is important for investigating anisotropic soil resistivity measurements (Samouëlian et al., 2004) and is considered relevant for recognising 3D objects (Senos Matias, 2002).

For the A level, seven Wen32 profiles were realised in the $x$ direction. The distance between two successive lines was $0.09 \mathrm{~m}$. The recorded apparent electrical resistivity measurements for one Wen32 profile resulted in 129 measurements at six pseudo-depths. The same measurement procedure with Wen32 was repeated for the $B$ and $C$ levels. The $x$ and $y$ coordinates of each Wen32 array did not change. temperature effects on the electrical measurements.

For the A level, four Wen16 profiles were realised in the y direction; these profiles were perpendicular to the Wen32 profiles. Seven Wen16 profiles were realised for the $\mathrm{C}$ level. For one Wen16 profile, each experiment resulted in 34 measurements that were distributed across four pseudo-depths.

At the $A$ and $C$ levels, the square array (Sqr32) was used. This sequence resulted in thirty measurements that were distributed across two pseudo-depths.

The temperature was recorded in the E\&Bt horizon during the experiments with PT100 probes. The temperature was constant during the electrical resistivity measurements and was approximately $9^{\circ} \mathrm{C}$. Thus, there is no need to consider

\subsection{Data processing}

\subsubsection{D inversion of the electrical resistivity data}

For each level, a complete dataset of georeferenced apparent resistivity measurements was built. This dataset included measurements from the Wen32, Wen16 and Sqr32 configurations. To obtain quantitative information regarding the resistivity distribution at the actual investigated depths, the apparent resistivity measurements were interpreted with the RES3DINV software (Geotomo Software, Malaysia) based on the Loke and Barker (1996) inversion procedure. To help detect 
Version définitive du manuscrit publié dans / Final version of the manuscript published in :

1 flatness filter was twice the horizontal flatness filter. We used a model with narrower cells, which is recommended when the resistivity varies greatly near the surface.

The $3 \mathrm{D}$ inversion of the electrical resistivity data provided a bloc diagram of 4 the interpreted electrical resistivity values for the three levels $A, B$ and $C$.

2.3.2. Processing of the soil photographs

All of the photographs were ortho-rectified to the same $(0, x, y, z)$ coordinates of the electrical resistivity data so that they could be compared. On each photograph, the ochre and white EPVs were separated by hand with a visual analysis. This analysis created binary images that could be used to count the proportion of each EPV and to evaluate the ability of the electrical resistivity measurements for identifying ochre and white EPVs. As included in the ochres ones, the black concretions were labelled as ochre ones in the binary images.

\subsubsection{Comparison between the electrical resistivity data and the soil photograph pictures}

To compare electrical resistivity data, which were in 3D, and soil photographs, which were in $2 \mathrm{D}$, we extracted $2 \mathrm{D}$ planes from the $3 \mathrm{D}$ bloc diagram of inverted electrical resistivity at a depth of $0.35,0.41$ and $0.47 \mathrm{~m}$ (i.e., at the $A, B$ and $C$ levels).

A variographic analysis was conducted on the three colour channels of the photographs that were taken at the surface of each level and on the 2D resistivity planes at depths of $0.35,0.41$ and $0.47 \mathrm{~m}$. For each variogram, the local and regional components were identified and used to create new datasets that corresponded to each spatial component, except for nugget (see Appendix for the complete description of the method).

Whatever the type of dataset (original dataset, local component dataset or regional component dataset), 2D resistivity data were compared to each channel of the photographs. 
Version définitive du manuscrit publié dans / Final version of the manuscript published in :

Geoderma, 2014, 219-220, 168-176

\subsection{Proportion of the EPVs at each level}

The corresponding binary images of the photographs of the three levels were used to determine the proportion of ochre and white EPVs (Figure 3). The proportions of the ochre EPVs were 46, 45 and 55\% for the A, B and C levels, respectively. A concentric zone (see the arrow symbol on the $\mathrm{C}$ level) with a higher proportion of white EPVs between 0.18 and $0.45 \mathrm{~m}$ along the Ox axis was observed, especially for the $\mathrm{C}$ level.

\subsubsection{D electrical resistivity}

The graphic representations of the planes that corresponded to the $A, B$ and $C$ level depths were obtained from the first layer of each inverted dataset for each $A$ or $B$ or $C$ levels (Figure 4). They exhibited resistivity values of between $15 \Omega$.m (i.e. 66 $\mathrm{mS} . \mathrm{m}^{-1}$ ) and $80 \Omega$ S.m (i.e. $12 \mathrm{mS} . \mathrm{m}^{-1}$ ). Generally, the resistivity values decreased with depth. For example, the resistivity values were higher for the A level (40 $\Omega . m$ on average i.e. $25 \mathrm{mS} . \mathrm{m}^{-1}$ ) than for the $B$ and $C$ levels (30 $\Omega . m$ on average i.e. 33 $\mathrm{mS} . \mathrm{m}-1)$. At each level, the resistivity values varied spatially.

On the $\mathrm{C}$ level, a more resistive zone of approximately $45 \Omega$.m (i.e. $22 \mathrm{mS}^{-1} \mathrm{~m}^{-1}$ ) was observed between 0.20 and $0.40 \mathrm{~m}$ along the Ox axis (see the arrow symbol), which corresponded to the location of the concentric zone that was previously described in section 2.2.

\subsection{Comparison between the electrical resistivity data and the photographs}

\subsubsection{Variographic analysis}

To compare the soil photographs at the three levels to the 2D planes from the 3D electrical resistivity inversion, the original, local component and regional component datasets were analysed. Figure 5 provides an example for level C.

We then analyse the coefficient correlation between the soil photograph pixel values for each colour channel and the $2 \mathrm{D}$ electrical resistivity values of the $2 \mathrm{D}$ planes that were extracted by 3D inversion for the A, B and C levels (Table 2). These correlation coefficients were calculated for the original, local component and regional 
Version définitive du manuscrit publié dans / Final version of the manuscript published in :

1 component datasets. The correlation coefficients were not significant (lower than 20.40 ) for the original or local component datasets for any of the colour channels or 3 levels.

In contrast, for levels $\mathrm{B}$ and $\mathrm{C}$, the correlation coefficients between the regional components of the photographs and the spatial components of resistivity maps were considered significant for all colour channels.

\subsubsection{Creation of a 3D soil structure image}

The 3D inverted resistivity values were interpolated using a 3D kriging routine. In addition, we proposed the following methodology to transform the electrical resistivity values into ochre and white EPVs. At each level, we separated the electrical resistivities into two classes with different threshold values and calculated the resulting proportions of ochre and white. The best threshold value should provide the ochre and white proportion that is closest to the one calculated from the binary photographs. For each level, the best agreement was observed when the threshold value corresponded to the mean resistivity value. Next, we used the mean value of the entire 3D resistivity dataset to discretise the 3D data into white and ochre EPVs.

Figure 6 contains the maps of agreement between the binary electrical resistivity data and the binary soil photographs. A large zone of agreement between 0.20 and $0.40 \mathrm{~m}$ along the Ox axis was observed that corresponded to the concentric zone position of the white EPVs.

This 3D discretisation (Figure 7) was composed of 43.8 and $56.2 \%$ of white and ochre electrical EPVs, respectively, which is consistent with the values obtained from the soil photographs at the three levels. In addition, these results were consistent with those were obtained by Montagne et al. (2007), who used image analysis on large impregnated blocks.

\section{Discussion}

\subsection{The structure of the heterogeneous horizon: what do we learn from electrical measurements?}


Version définitive du manuscrit publié dans / Final version of the manuscript published in :

The use of electrical resistivity in soil science studies has one considerable advantage over the use of geological studies because non-destructive and rapid observations of the structure are feasible. The E\&Bt horizon appears to be a good case study because the electrical resistivity values are highly heterogeneous.

For our experiment, several soil characteristics, including the bulk density, the clay content and the water content, were determined. The clay contents were significantly higher in the ochre than in the white EPVs, which should result in lower resistivity values in the ochre EPVs. For the water and the bulk density, the maximum differences between the white and ochre EPVs were $0.005 \mathrm{~g} . \mathrm{g}^{-1}$ and $0.06 \mathrm{~g}_{\mathrm{cm}} \mathrm{cm}^{-3}$, respectively (Table 1). Such small variations cannot be detected by the electrical resistivity measurements (Seladji et al., 2010). Thus, we can assume that only the soil texture (due to its clay content) would induce large soil electrical variations. Incidentally, soil texture measurements throughout the soil profile indicated that the clay content increased with depth due to the decreasing white volumes. This finding is consistent with the general decrease in resistivity with depth.

The comparisons between the photographs of each level and the interpreted electrical resistivity measurements did not lead to significant results when the raw values or the local components of the two datasets were considered. Indeed, the precise geometrical limits of the EPVs were not detected by the electrical resistivity because of either the inter-electrode spacing or the loss of information with depth. In contrast, because the ERT method is integrative, these comparisons were more relevant for the regional components of the two datasets. The current lines are threedimensional and represent a certain soil volume whose size increases and resolution decreases as the inter-electrode spacing increases. As a result, this method is efficient for locating large areas (several centimetres) of white or ochre soil volumes without determining their exact local geometry. Regarding geometry, the electrical structure exhibits large electrical resistivity values that correspond to white volumes near the surface and along the Ox axis (i.e., parallel to the surface plane). Deeper, the large resistivity values are organised by geometrical volumes and are oriented more along the $\mathrm{Oz}$ axis (i.e., along a vertical axis). This orientation is consistent with the general organisation of the E\&Bt horizon in an Albeluvisol. Near the soil surface, the amount of white EPVs (i.e. albeluvic tongues) is greater. These white volumes are less numerous and more vertical. In addition, they occur in tongues that range from a few centimetres to several tens of centimetres in size (WRB, 1998). These 
Version définitive du manuscrit publié dans / Final version of the manuscript published in :

1 tongues have a higher hydraulic conductivity than the ochre volumes and constitute 2 preferential pathways for water transfer (Frison et al., 2009). According to the field 3 observations of several authors, the functionality of some of these tongues depends 4 of their texture (Diab et al., 1988). However, these differences are difficult to identify 5 from soil profile photographs. Based on the electrical structure analyses of the 6 tongues, lower electrical resistivities corresponded to higher hydraulic conductivities. 7 To interpret the electrical resistivity in terms of hydraulic conductivity, some 8 complementary measurements are necessary, such as the water content and the 9 resistivity of several soil volumes. Nevertheless, the 3D structure of a heterogeneous horizon, which is derived from electrical measurements, contains a relevant 3D structure of the hydraulic properties. Thus, this 3D structure could be used to model the water transfer at this scale, as demonstrated by Samouëlian et al. (2011).

\subsection{Determination of the structure's Representative Elementary Volume} (REV)

Modelling the hydric function of the horizon with albeluvic tonguing is only feasible if (i) the structure is studied in 3D and, (ii) the volume of studied soil is greater than the Representative Elementary Volume (REV). It is possible that the REV of some hydric properties is different than the REV of some structural characteristics. However, we can determine if this difference occurs by determining if the volume analysed by electrical resistivity is greater than the REV that is necessary to describe the horizon morphology (i.e., the 3D geometrical arrangement of the ochre and the white EPVs).

From the 3D resistivity values, a variogram was calculated for each direction (Ox, Oy, Oz) (Figure 8) to represent the distribution of the ochre and white EPVs based on distance. A limit value was observed at a distance of $0.25 \mathrm{~m}$ for both variograms in the $\mathrm{Ox}$ and $\mathrm{Oz}$ directions. This result indicated that the REV for the horizon structure was reached. In addition, this value was consistent with the value obtained by Montagne et al. (2007) from 2D images of the same horizon. In contrast, the REV was not reached in the Oy direction. Thus, further investigations are needed to determine the exact structure in the Oy direction.

\section{Conclusions}


Version définitive du manuscrit publié dans / Final version of the manuscript published in :

ERT surveys were conducted on a highly heterogeneous horizon over a surface area of approximately one square metre. The E\&Bt horizon of an Albeluvisol was studied with 3D electrical resistivity prospecting.

The studied horizon had a complex structure composed of a juxtaposition of silty white and clayey ochre EPVs. We demonstrated that the resistivity of the white EPV was larger than the resistivity of the ochre EPV. In addition, the structure of the soil horizon can be derived from electrical resistivity data. Nevertheless, to obtain accurate electrical measurements that could describe the horizon structure, our work required the destruction of the studied soil. Other destructive methods, such as serial sectioning with numerical photograph analysis, could also be used to produce the 3D structure of the studied horizon. However, more electrodes could be used in the future to improve the accuracy of the ERT measurements without disturbing the soil horizon.

The resistivity was higher in the upper portion of the studied horizon. In this layer, zones were identified that were parallel to the surface and corresponded to the white EPVs. The resistivity was lower at depth due to the higher amount of ochre EPVs. However, the white EPVs occurred in structures that were predominantly orientated perpendicular to the soil surface, similarly to tongues. Depending on their actual texture, these tongues may or may not transfer water. Electrical resistivity measurements could enable the identification of functional tongues if they are collected several times during infiltration or evaporation periods. In the future, the 3D structure of such a complex horizon obtained by electrical resistivity measurements will improve water and solute transport models.

\section{Acknowledgments}

Guillaume Giot, Christian Lelay, Sophie Cornu and Anatja Samouëlian are gratefully acknowledged for their help with field experiments and laboratory measurements. 
Version définitive du manuscrit publié dans / Final version of the manuscript published in :

1 References

2 Abu-Hassanein, S., Benson, H., Blotz, R., 1996. Electrical resistivity of compacted 3 clays. J. Geotec. Eng. 122, 397-407.

4 Besson, A., Cousin, I., Samouëlian, A., Boizard, H., Richard, G., 2004. Structural heterogeneity of the soil tilled layer as characterized by 2D electrical resistivity surveying. Soil and Tillage Research 79, 239-249.

Blake, G.R., Hartge, K.H., 1986. Bulk density, in: Klute, A. (Ed.), Methods of Soil Analysis. Part 1, second ed. Agron. Monogr. 9. ASA and SSSA, Madison, WI, pp.363-375.

Bockheim, J.G., Gennadiyev, A.N., Hammer, R.D., Tandarich, J.P., 2005. Historical development of key concepts in pedology. Geoderma 124, 23-36.

Bourennane, H., Nicoullaud, B., Couturier, A., Pasquier, C., Mary, B., King, D., 2012. Geostatistical filtering for improved soil water content setimation from electrical

Cousin, I., Levitz, P., Bruand, A., 1996. Three-dimensional analysis of a loamy-clay soil using pore and solid chord distributions. Eur. J. Soil Sci. 47, 439-452.

Cousin, I., Nicoullaud, B., Coutadeur, C., 2003. Influence of rock fragments on the water retention and water percolation in a calcareous soil. Catena 53, 97-114.

Dahlin, T., 2001. The development of DC resistivity imaging techniques. Comput. Geosci. 27, 1019-1029.

Dahlin, T., Zhou, B., 2004. A numerical comparison of 2D resistivity imaging with 10 electrode arrays. Geophys. Prospecting 52, 379-398.

Diab, M., Merot, P., Curmi, P., 1988. Water movement in a glossaqualf as measured by two tracers. Geoderma 43, 143-161.

Forrer, I., Papritz, A., Kasteel, R., Flühler H., Luca, D., 2000. Quantifying dye tracers in soil profiles by image processing. Eur. J. Soil Sci.51, 313. 
Version définitive du manuscrit publié dans / Final version of the manuscript published in :

1 Frison, A., Cousin, I., Montagne, D., Cornu, S., 2009. Soil hydraulic properties in

2 relation to local rapid soil changes induced by field drainage: a case study. Eur. J.

3 Soil Sci.60, 662-670.

4 Goovaerts, P., 1997. Geostatistics for Natural resources Evaluation. Oxford

$5 \quad$ University Press.

6 Jamagne, M., King, D., 2003. The current French approach to soilscape typology, in:

7 Eswaran, H., Rice, T., Ahrens, R., Stewart, B.A. (Ed.), Soil Classification. A

$8 \quad$ Global Desk Reference. CRC Press, New York, pp.157-178.

9 Loke, M.H., 2001. Tutorial : 2D and 3D electrical imaging surveys. Course Notes for 10 USGS Workshop "2D and 3D inversion and modelling of Surface and Borehole 11 Resistivity Data", Torrs, CT, 59 pp.

12 Loke, M.H., Barker, R.D., 1996. Rapid least-squares inversion of apparent resistivity 13 pseudosections using a quasi-Newton method. Geophys. Prospecting 44, 131$14 \quad 152$.

Montagne, D., Cousin, I., Le Forestier, L., Daroussin, J., Cornu, S., 2007.

Quantification of soil volumes in the Eg\&Bt-horizon of an Albeluvisol using image analysis. Can. J. Soil Sci. 87, 51-59.

Montagne, D., Cornu, S., Le Forestier, L., Hardy, M., Josière, O., Caner, L., Cousin, I., 2008. Impact of drainage on soil-forming mechanisms in a French Albeluvisol: input of mineralogical data in mass-balance modelling. Geoderma 145, 426-438.

Nemes, A., Schaap, M.G., Leij, F.J., Wosten, J.H.M., 2001. Description of the unsaturated soil hydraulic database UNSODA version 2.0. J. Hydrol. 25, 151-162.

Pereira, V., FitzPatrick, E.A., 1998. Three-dimensional representation of tubular horizons in sandy soils. Geoderma 81, 295-303. 
Version définitive du manuscrit publié dans / Final version of the manuscript published in :

1 Petrovic, A.M., Siebert, J.E., Rieke, P.E., 1982. Soil bulk density analysis in three dimensions by computed tomographic scanning. Soil Sci. Soc. Am. J. 46, 445450.

Rey, E., Jongmans, D., Gotteland, P., Garambois, S., 2006. Characterisation of soils with stony inclusions using geoelectrical measurements. J. Appl. Geophys. 58, 188-201.

Richard, G., Cousin, I., Sillon, J.F., Bruand, A., Guerif, J., 2001. Effect of compaction on the porosity of a silty soil: influence on unsaturated hydraulic properties. Eur. J. Soil Sci.52, 49-58.

Roger-Estrade, J., Richard, G., Caneill, J., Boizard, H., Coquet, Y., Defossez, P., Manichon, H., 2004. Morphological characterisation of soil structure in tilled fields: Till.Res. 79, 33-49.

Samouëlian, A., Cousin, I., Tabbagh, A., Bruand, A., Richard, G., 2005. Electrical resistivity survey in soil science: a review. Soil Till.Res. 83, 173-193.

Samouëlian A., Cousin I., Dagès C., Frison A., Richard G., 2011. Determining the effective properties of a highly heterogeneous horizon. Vadose Zone J., 10, 450 458.

Samouëlian, A., Richard, G., Cousin, I., Guérin, R., Bruand, A., Tabbagh, A., 2004. Three-dimensional crack monitoring by electrical resistivity measurement. Eur. J. Soil Sci.55, 751-762.

Séger, M., Cousin, I., Frison, A., Boizard, H., Richard, G., 2009. Characterisation of the structural heterogeneity of the soil tilled layer by using in situ 2D and 3D electrical resistivity measurements. Soil Till.Res. 103, 387-398. 
Version définitive du manuscrit publié dans / Final version of the manuscript published in :

1 Seladji, S., Cosenza, P., Tabbagh, A., Ranger, J., Richard, G., 2010. The effect of 2 compaction on soil electrical resistivity: a laboratory investigation. Eur. J. Soil $3 \quad$ Sci.61, 1043-1055.

4 Senos Matias, M.J., 2002. Square array anisotropy measurements and resistivity sounding interpretation. J. Appl. Geophys. 49, 185-194.

6 Trojan, M.D., Linden, D.R., 1998. Macroporosity and hydraulic properties of earthworm-affected soils as influenced by tillage and residue management. Soil Sci. Soc. Am. J. 62, 1687-1692.

9 Vogel, H.J., Cousin, I., Roth, K., 2002. Quantification of pore structure and gas diffusion as a function of scale. Eur. J. Soil Sci.53, 465-473.

Wackernagel, H., 1998. Multivariate geostatistics. Springer-Verlag.

Wösten, J.H.M., Lilly, A., Nemes, A., Le Bas, C., 1999. Development and use of a database of hydraulic properties of European soils. Geoderma 90, 169-185.

WRB, 1998. A world reference base for soil resources, in: Deckers, J.A., Spaargaren, O.C., Nactergaele, F.O., Oldeman, L.R., Brinkman, R. (Ed.), World soil resources reports n`84. FAO-ISRIC-AISS. Rome, Italia. 
Version définitive du manuscrit publié dans / Final version of the manuscript published in :

\section{Appendix}

Indeed, a spatial random process can be a combination of several constituent random processes one nested within another and acting different charachteristic spatial scales. In these circumstances the variogram of a random function $Z(\mathbf{x})$ is a nested combination of two or more individual variograms leading to so-called nested variogram that displays different structures (e.g. different ranges of spatial dependence). The variogram can thus be modelled as the sum of $L+1$ basic variograms (e;g. Goovaerts, 1997; Bourennane et al., 2012), each corresponding to a disctinct spatial structure:

$$
\gamma(\mathbf{h})=\sum_{l=0}^{L} \gamma_{l}(\mathbf{h})=\sum_{l=0}^{L} b_{l} \gamma_{l}(\mathbf{h}) \quad \text { with } \quad b_{l} \geq 0
$$

where ${ }^{b_{l}}$ is the variance of the corresponding basic variogram model $\gamma_{l}(\mathbf{h})$. The variance corresponding to $I=0$ is called nugget and represents the spatial unstructured part of the total variance. Based on the linear model of regionalization (1), the random function $Z(\mathbf{x})$ can be decomposed into a sum of $(L+1)$ independent random functions, called spatial component, and its local mean $\mathrm{m}(\mathrm{x})$ :

$$
Z(\mathbf{x})=\sum_{l=0}^{L} Z_{l}(\mathbf{x})+m(\mathbf{x})
$$

where $Z_{l}(\mathbf{x})$ is the lth spatial component corresponding to the variogram model $\gamma_{l}(\mathbf{h})$. Each spatial component can thus be individually mapped by filtering out the other components. The estimator of the Ith spatial component of variable $Z$ at location $\times 0$ is:

$$
Z_{i}^{*}\left(\mathbf{x}_{0}\right)=\sum_{\alpha=1}^{n} w_{\alpha, l} Z\left(\mathbf{x}_{\alpha}\right)
$$

with $\mathrm{n}$ the number of observations around $\mathrm{x} 0$ involvd in the estimation where each observation receiving a weight ${ }^{w_{\alpha, l}}$. As the available observations $z\left(\mathbf{x}_{\alpha}\right)$ contain the contribution of all $L+1$ components which are considered mutually independent, only the contribution of the Ith component must be taken into account in the right hand side term of the kriging system. Moreover to ensure unbiased estimations and provided the variogram model $\gamma_{l}(\mathbf{h})$ is bounded (stationary case), the 
Version définitive du manuscrit publié dans / Final version of the manuscript published in :

1 kriging weights ${ }^{w_{\alpha, l}}$ must sum to zero, and not to one as in ordinary kriging

2 (Wackernagel, 1998). This leads to the following kriging system for lth component:

$$
\left\{\begin{array}{l}
\sum_{\beta=1}^{n} w_{\beta, l} \gamma\left(\mathbf{x}_{\alpha}-\mathbf{x}_{\beta}\right)+\phi_{l}=b_{l} \gamma_{l}\left(\mathbf{x}_{\alpha}-\mathbf{x}_{0}\right) \quad \text { for } \alpha=1, \ldots, n \\
\sum_{\beta=1}^{n} w_{\beta, l}=0
\end{array}\right.
$$

$4 \quad$ where $\phi_{l}$ is the Lagrange parameter for the lth component. This system of $5 \mathrm{n}+1$ equations must be solved to find the weights ${ }^{w_{\beta, l}}$ that are then inserted into 6 equation (4) to estimate the Ith spatial component of variable $Z$ at location $\times 0$. The 7 operation is repeated for all locations where such decomposition is required. 
Version définitive du manuscrit publié dans / Final version of the manuscript published in :

\section{Figures captions:}

Figure 1:3D representation of the soil profile. The underlined white zones correspond to some white EPVs. The ochre EPVs were juxtaposed to the white ones.

Figure 2: Experimental design. Location of the Wen32, Wen16 and Sqr32 electrodes at each studied level.

Figure 3: Photographs of the three surface levels (-a-, -c- and -e-) and their corresponding binary representations (-b-, - $d$ - and -f-) for white and ochre EPVs after the visual analysis. The surface proportions of the white and ochre EPVs are mentioned.

Figure 4: Interpreted electrical resistivity for the three levels extracted from the inverted electrical resistivity 3D data.

Figure 5: Comparisons of the electrical resistivity planes and the real surface level photographs. For example, the $\mathrm{C}$ level between the resistivity plane that was extracted from the 3D data and the blue channel of the real photograph were compared. The comparisons are made on the original images (-a- and - $d-$ ) and on the local (-b- and -e-) and regional components (-c- and -f-) that were obtained from variographic analysis. For conductivity equivalent values, see Figure 4.

Figure 6: Map of agreement between the binary classifications that were determined from visual analysis and from electrical resistivity maps separated by the threshold value.

Figure 7: A 3D representation of the electrical structure discretisation in two EPVs.

Figure 8: Variograms of the 3D block of the electrical resistivity discretised for the three Ox, Oy and Oz directions. 
Version définitive du manuscrit publié dans / Final version of the manuscript published in :

2 Table 1: Soil characteristics for the white and ochre EPVs. The standard errors of 3 measurements are presented in brackets.

\begin{tabular}{|c|c|c|c|c|c|c|}
\hline & \multicolumn{2}{|c|}{ Bulk density $\left(\mathrm{g} \mathrm{cm}^{-3}\right)$} & \multicolumn{2}{c|}{ Clay content $\left(\mathrm{g} \mathrm{kg}^{-1}\right)$} & \multicolumn{2}{c|}{ Field water content $\left(\mathrm{g} \mathrm{g}^{-1}\right)$} \\
\hline $\begin{array}{c}\text { Depth } \\
(\mathrm{m})\end{array}$ & $\begin{array}{c}\text { White } \\
\text { EPV }\end{array}$ & $\begin{array}{c}\text { Ochre } \\
\text { EPV }\end{array}$ & $\begin{array}{c}\text { White } \\
\text { EPV }\end{array}$ & $\begin{array}{c}\text { Ochre } \\
\text { EPV }\end{array}$ & $\begin{array}{c}\text { White } \\
\text { EPV }\end{array}$ & $\begin{array}{c}\text { Ochre } \\
\text { EPV }\end{array}$ \\
\hline $0.35-0.45$ & $1.61(0.06)$ & $1.63(0.02)$ & 182 & 248 & $0.211(0.01)$ & $0.206(0.01)$ \\
\hline $0.45-0.55$ & $1.59(0.02)$ & $1.65(0.03)$ & 213 & 322 & $0.209(0.01)$ & $0.205(0.01)$ \\
\hline
\end{tabular}

Table 2: Correlation coefficients between the colour channel pixels of the numerical photographs and the interpreted resistivity of the $x-y$ maps that were extracted from the $3 D$ data in the $A, B$ and $C$ levels (at $z$ coordinates of $0.35,0.41$ and $0.47 \mathrm{~m}$ respectively). The comparisons were made for the raw data, the local and regional components of each level.

\begin{tabular}{|c|c|c|c|}
\hline \multicolumn{5}{|c|}{ Level A (0.35 m) } \\
\hline Correlation & Red channel & Green channel & Blue channel \\
\hline Raw data & 0.05 & 0.09 & 0.08 \\
\hline Local component & 0.01 & 0.02 & 0.02 \\
\hline Regional component & 0.14 & 0.21 & 0.20 \\
\hline
\end{tabular}

4

\begin{tabular}{|c|c|c|c|}
\hline \multicolumn{5}{|c|}{ Level B (0.41 m) } \\
\hline Correlation & Red channel & Green channel & Blue channel \\
\hline Raw data & 0.23 & 0.27 & 0.27 \\
\hline Local component & 0.08 & 0.15 & 0.18 \\
\hline Regional component & $0.55^{*}$ & $0.64^{*}$ & $0.64^{*}$ \\
\hline
\end{tabular}

\begin{tabular}{|c|c|c|c|}
\hline \multicolumn{5}{|c|}{ Level C (0.47 m) } \\
\hline Correlation & Red channel & Green channel & Blue channel \\
\hline Raw data & 0.32 & 0.40 & 0.39 \\
\hline Local component & 0.21 & 0.33 & 0.35 \\
\hline Regional component & $0.71^{*}$ & $0.75^{*}$ & $0.76^{*}$ \\
\hline
\end{tabular}

